\title{
Prolongation of greater occipital neural blockade with $10 \%$ lidocaine neurolysis: a case series of a new technique
}

This article was published in the following Dove Press journal: Journal of Pain Research

29 September 2016

Number of times this article has been viewed

\author{
David Daewhan Kim \\ Nabil Sibai \\ Department of Anesthesiology/ \\ Pain Medicine Division, Henry Ford \\ Hospital, Detroit, MI, USA
}

Correspondence: David Daewhan Kim Department of Anesthesiology/Pain Medicine Division, Henry Ford Hospital (I-3 Pain Clinic), 2799 W Grand Blvd, Detroit, MI 48208, USA

Tel +l 2483448000

Email Dkim I@hfhs.org
Introduction: Greater occipital nerve blocks (GONB) have been used for headache but their benefit may be short. Ready et al performed intrathecal injections on rabbits and reported neurologic/histologic changes that required concentrations of at least $8 \%$. Our study tests the hypothesis that the neurolytic effects of GONB with $10 \%$ lidocaine can prolong relief.

Methods: After an approval from Henry Ford Hospital Institutional Review Board, a chart review was performed for patients who had GONB with $10 \%$ lidocaine. Patients received $10 \%$ lidocaine after short response ( $<1$ month / $>50 \%$ relief) to GONB with $1 \mathrm{cc}$ of a solution containing $9 \mathrm{~mL}$ $0.5 \%$ bupivacaine and $40 \mathrm{mg}$ methylprednisolone. They received a block with $10 \%$ lidocaine with volume given at $<80 \%$ of the maximum dose of $4 \mathrm{mg} / \mathrm{kg}$. Injections were performed under fluoroscopic guidance after injection of $0.1 \mathrm{cc}$ of contrast (isovue or magnevist). All patients had intravenous access and were given fentanyl and midazolam. The visual analog scale (VAS) scores were recorded on follow-up, and the duration of response was noted. VAS changes with $10 \%$ lidocaine and comparison of duration with methylprednisolone were performed using paired $t$-test. Results: Thirteen patients were reviewed; 12 were female and the mean age was 47 . Ten were diagnosed with migraine, and three with occipital neuralgia; 12 had bilateral symptoms. Baseline VAS prior to $10 \%$ lidocaine averaged $86.92 \mathrm{~mm}$. The mean volume injected per nerve was $1.096 \mathrm{~mL}$. There was significant decrease in mean $\%$ VAS with $10 \%$ lidocaine at $60.4 \%$ (mean: $-52.69 \mathrm{~mm})(P=0.001)$. The mean duration of relief was significantly higher with $10 \%$ lidocaine at 148.05 days ([standard deviation $]=98.87$ ) versus methylprednisolone at 6.33 days (standard deviation=5.01) $(P=0.001)$. No complications or side effects were reported.

Conclusion: Ten percent lidocaine may be a useful neurolytic agent in prolonging the duration of GONB.

Keywords: pain relief, migraines, occipital neuralgia, intractable headaches, injections

\section{Introduction}

Chronic migraine and occipital neuralgia are common causes of intractable headache with prevalence of $(1.4 \%-2.2 \%)$ for migraine and $(0.4 \%-4 \%)$ for occipital neuralgia. ${ }^{1,2}$ Medication management has traditionally been limited in efficacy, tolerability, and compliance. ${ }^{3}$ Greater occipital nerve blocks (GONB) have been used to treat various headache syndromes such as migraine, greater occipital nerve (GON), cluster headache, cervicogenic headache, and even dural puncture headache that are refractory to other treatments. ${ }^{3-7}$ The mechanism of action has been speculated to be due to the convergence of sensory afferents from $\mathrm{C} 2$ and the trigeminal nerve. ${ }^{8,9}$ The duration of pain relief obtained from GONB has been shown to be quite variable and short 
in duration. Lambru et al in a prospective open-label study of cluster headache patients reported a mean duration of 21 days. $^{6}$ Siddiqui and Caplinger evaluated the efficacy of occipital nerve blocks for chronic migraine with and without bupivacaine, and reported mean duration of either 23.7 and 22.6 days, respectively, with a range of $1-90$ days. ${ }^{10}$ Afridi et al performed GONB for various primary headache syndromes and reported a mean duration of partial response of 61 days. ${ }^{11}$ Due to the short duration of relief with GONB, radiofrequency ablation (RFA) using pulsed, cooled, and continuous ablation has been used to prolong relief. ${ }^{12-16}$ However, these are not without complications, especially with continuous RFA, which can cause post-denervation neuralgia. ${ }^{12-16}$ Due to the current fiscal environment in the US, alternatives such as cooled and pulsed RFA may not be reimbursed by insurance. The use of chemical neurolysis with phenol and alcohol in the thin tissue of the GON may be problematic given the risk of anesthesia dolorosa and necrosis of surrounding soft tissue. ${ }^{17-19}$ Lidocaine has been demonstrated to be neurotoxic in multiple animal and cell culture studies. ${ }^{20-34}$ Ready et al in 1985 performed intrathecal injections of $2 \%-32 \%$ lidocaine on rabbits and followed neurologic function for 7 days prior to harvesting the spinal cords for histology. ${ }^{24}$ They reported persistent neurologic deficit and major histologic changes starting at $8 \%$ concentration. The reports of clinical use of higher concentration lidocaine for chronic pain were highly limited. Choi and Liu reported three cases of patients who had months of relief with peripheral nerve blocks of $5 \%$ lidocaine with 7.5 dextrose. ${ }^{35}$ Only one of the cases was a GONB for post-herpetic neuralgia, which lasted 8 months. Their study was problematic given the small number and the concentration used by Choi was less than the $8 \%$ concentration threshold for neurolysis seen in animal study by Ready et al. Also Hempl et al demonstrated that the addition of dextrose and lower concentration lidocaine did not show consistent neurolytic symptoms in the context of increased transient neurologic symptoms (TNS) in spinal anesthesia. ${ }^{36} \mathrm{Kim}$ et al demonstrated that $10 \%$ lidocaine caused rapid neurolytic changes in the sciatic nerve in a canine. ${ }^{37}$ Therefore, this study tests the hypothesis that lidocaine $>8 \%$ concentration can be an alternative neurolytic agent in the prolongation of headache relief with GONB in a retrospective chart review.

\section{Methods}

After Institutional Review Board at Henry Ford Hospital (Detroit MI) approval, a retrospective chart review was performed on all patients who received GONB with $10 \%$ preservative-free lidocaine for headache from January 2014 to June 2015 after referral for occipital nerve block from neurology service. Ten percent preservative-free lidocaine was compounded by Health Dimensions Compounding Pharmacy (Farmington, MI, USA). Those patients who received 10\% lidocaine had to have $\geq 50 \%$ relief on visual analog scale (VAS) for $<1$ month with GONB using bupivacaine/methylprednisolone (BM). Demographic information including age, sex, laterality, diagnosis, and baseline VAS prior to $10 \%$ lidocaine GONB was recorded. As per routine in our clinic, patients were asked to follow-up once they felt the headaches had return to baseline. On follow-up, the VAS during the period of relief and duration of relief as reported by patients was recorded. Duration of relief with initial GONB with BM was noted. All GONB were performed by the same provider. GONB with BM were performed at the bedside. After written informed consent was obtained for the whole study as per standard practice of care, GONB with $10 \%$ lidocaine was performed with the patients in prone position in a cervical headrest under fluoroscopic guidance to exclude vascular uptake with sedation of intravenous fentanyl and midazolam. The volume of $10 \%$ lidocaine used was up to $80 \%$ max dose of lidocaine based on $4 \mathrm{mg} / \mathrm{kg}$ body weight, and $0.1 \mathrm{cc}$ isovue or magnevist contrast was injected prior to exclude vascular uptake to reduce the risk of lidocaine toxicity. Of note, patients who received bilateral GONB received a smaller dose/volume of $10 \%$ lidocaine due to the dose limit of $4 \mathrm{mg} / \mathrm{kg}$. Statistical analysis was performed using paired $t$-test.

\section{Results}

A total of 13 patients were reviewed. All but one patient was female, and the average age was 47 years (standard deviation $[\mathrm{SD}]=15.42$ ) (Table 1). Ten were diagnosed with migraine and three with occipital neuralgia. Eleven had bilateral symptoms (Table 1). Baseline VAS prior to GONB with $10 \%$ lidocaine averaged $86.92 \mathrm{~mm}(\mathrm{SD}=11.82)$ (Table 2). The mean volume of $10 \%$ lidocaine injected per nerve was 1.096 $\mathrm{mL}(\mathrm{SD}=0.38)$ (Table 1). There was significant decrease in mean \% change VAS with $10 \%$ lidocaine at $60.4 \%$ (mean: $-52.69 \mathrm{~mm})(P=0.001)$ (Table 2$)$. The mean duration of relief was significantly higher with $10 \%$ lidocaine at 148.05 days $(\mathrm{SD}=98.87)$ versus $\mathrm{BM}$ at 6.33 days $(\mathrm{SD}=5.01)(P=0.001)$ (Table 3 ). No complications or side effects were reported.

\section{Discussion}

\section{Relationship of concentration of lidocaine and neurolysis}

Most animal studies have used concentrations of $5 \%$ or less to study neurotoxicity since this is the most common concentration used clinically. Previous studies used direct intraneural or intrathecal injections, desheathed nerves, and cell cultures. Only one paper by Kalichman et al mentions 
Table I Patient demographics and dose of 10\% lidocaine used

\begin{tabular}{|c|c|c|c|c|c|}
\hline Diagnosis & Male $=I$ & Female $=I$ & Age & Bilateral $=I$ & $\begin{array}{l}\text { Dose }(\mathrm{mL}) \text { per site } \\
10 \% \text { lidocaine }\end{array}$ \\
\hline Migraine & 0 & I & 19 & 0 & 1.5 \\
\hline Migraine & 0 & I & 38 & I & I \\
\hline Migraine & 0 & I & 45 & I & I \\
\hline Migraine & 0 & 1 & 67 & I & 1 \\
\hline Migraine & 0 & 1 & 48 & I & I \\
\hline Migraine & 0 & I & 52 & I & I \\
\hline Migraine & 0 & I & 65 & I & 1 \\
\hline Occipital & 0 & 1 & 69 & I & 0.75 \\
\hline Migraine & 0 & 1 & 57 & 1 & 1 \\
\hline Migraine & 1 & 0 & 36 & I & 1.5 \\
\hline Occipital & 0 & 1 & 35 & 0 & 2 \\
\hline Migraine & 0 & I & 28 & I & I \\
\hline Occipital & 0 & I & 52 & 1 & 0.5 \\
\hline Migraine $(\mathrm{N}=10)$ Occipital $(\mathrm{N}=3)$ & Male $=I$ & 12 & Mean $=47$ & Bilateral=I I & Mean $=1.096154$ \\
\hline
\end{tabular}

Table 2 VAS baseline and post 10\% lidocaine

\begin{tabular}{|c|c|c|c|c|}
\hline Diagnosis & $\begin{array}{l}\text { Base VAS before } \\
10 \% \text { lidocaine }(\mathrm{mm})\end{array}$ & $\begin{array}{l}\text { Post-VAS after } \\
10 \% \text { lidocaine }(\mathrm{mm})\end{array}$ & Change VAS (mm) & $\%$ change VAS \\
\hline Migraine & 80 & 20 & 60 & 75 \\
\hline Migraine & 90 & 22.5 & 67.5 & 75 \\
\hline Migraine & 100 & 62.5 & 38.5 & 38.5 \\
\hline Migraine & 100 & 60 & 40 & 40 \\
\hline Migraine & 70 & 40 & 30 & 40.4 \\
\hline Migraine & 90 & 50 & 40 & 44.4 \\
\hline Migraine & 70 & 30 & 40 & 57.14 \\
\hline Occipital & 80 & 30 & 50 & 62.5 \\
\hline Migraine & 90 & 22.5 & 67.5 & 75 \\
\hline Migraine & 90 & 22.5 & 67.5 & 75 \\
\hline Occipital & 100 & 25 & 75 & 75 \\
\hline Migraine & 70 & 30 & 40 & 57.2 \\
\hline Occipital & 100 & 30 & 70 & 70 \\
\hline Mean & 86.9230769 & 34.2307692 & 50.25 & $60.39538462(P=0.000 \mathrm{I})$ \\
\hline SD & 11.82 & 14.48 & 15.56 & 15.10 \\
\hline
\end{tabular}

Abbreviations: SD, standard deviation; VAS, visual analog scale.

Table 3 Comparison duration of maintenance of pain relief of bupivacaine/methylprednisolone test block with $10 \%$ lidocaine

\begin{tabular}{llll}
\hline Diagnosis & $\begin{array}{l}\text { Duration } \\
\text { from test } \\
\text { block (days) }\end{array}$ & $\begin{array}{l}\text { Duration } \\
\text { from I0\% } \\
\text { lidocaine (days) }\end{array}$ & $\begin{array}{l}\text { Change in } \\
\text { duration (days) }\end{array}$ \\
\hline Migraine & 14 & 210 & +196 \\
Migraine & 0.333 & 365 & +364.667 \\
Migraine & 2 & 220 & +218 \\
Migraine & 1 & 71 & +70 \\
Migraine & 7 & 24 & +17 \\
Migraine & 14 & 287 & +273 \\
Migraine & 4 & 60 & +56 \\
Occipital & 7 & 123 & +116 \\
Migraine & 7 & 120 & +113 \\
Migraine & 7 & 90 & +83 \\
Occipital & 4 & 221 & +217 \\
Migraine & 1 & 96 & +95 \\
Occipital & 14 & 120 & +106 \\
Mean & 6.333307692 & 154.3846154 & +149.05 \\
SD & 5.01 & 98.87 & $(P$-value=0.000I) \\
\hline
\end{tabular}

Abbreviation: SD, standard deviation. lidocaine being injected perineurally by piercing the connective tissue separating the neural tissue from overlying muscle rat sciatic nerves. ${ }^{22}$ They measured nerve conduction post-injection and performed histologic analysis at 48 hours. They reported endoneurial edema, collapsed myelin sheaths, and axonal degeneration. This study, however, used a lower concentration than seen in previous studies at $3 \%$ lidocaine. Although animal models have shown evidence of neurotoxicity at clinically used concentrations of $5 \%$ or less, evidence of neurotoxicity in humans at these concentrations appeared to be much less than expected. This has been well documented in the use of intrathecal lidocaine for spinal anesthesia and the phenomenon of TNS. Schneider et al reported four cases of TNS using 5\% lidocaine. ${ }^{34}$ Keld et al compared 5\% lidocaine versus $0.5 \%$ bupivacaine and found that lidocaine caused TNS in $26 \%$ of patients versus $3 \%$ in bupivacaine. ${ }^{38}$ Several prospective studies noted TNS incidence of $4 \%-33 \%$ with lidocaine. ${ }^{30,31}$ This may be explained by the study of Ready 
et al who reported prolonged neurologic deficit and profound histological changes after intrathecal injection in rabbits occurred only at lidocaine concentrations $\geq 8 \%$, which was compatible with the previously mentioned clinical experience in humans. In our study, 10\% lidocaine allowed local concentrations $\geq 8 \%$ despite the requirement to inject contrast beforehand to exclude vascular uptake.

\section{Extraneural local toxicity of lidocaine}

Our study did not find gross acute changes to the surrounding soft tissue after injection. Phenol and alcohol have been well known to cause significant necrosis in tissue other than neural tissue. Besides the obvious cardiac and central nervous system toxicity with lidocaine, which was controlled in our study by dose and image guidance, review of literature does not indicate significant soft tissue injury with lidocaine. Only two case reports or series have been published in the ophthalmology literature with cases of ptosis and diplopia after lidocaine injection for retro-orbital nerve blocks causing what is presumed to be due to ocular muscle necrosis but not proven by biopsy. ${ }^{32,33}$ Sahai-Srivastava and Subhani reviewed the side effects of different concentrations of lidocaine in their retrospective analysis of 89 patients who received GONB with $1 \%(\mathrm{~N}=69), 2 \%(\mathrm{~N}=18)$, and GONB with $5 \%$ lidocaine. ${ }^{39}$ They reported adverse effects such as dizziness, hypertension, blurry vision, slurred speech, and pseudo-seizure in $9 \%$ of patients with four patients in the $5 \%$ group and three in the $1 \%$ group. They reported no statistically significant correlation between lidocaine dose and occurrence of adverse effects, though there was a slight trend toward more adverse effects in the lidocaine 5\% group $(P=0.072)$ compared to the lidocaine 1\% group. Their study was limited since it did not mention the total $\mathrm{mg}$ of lidocaine used or volume. In our study, the risk of inadvertent vascular was decreased by using contrast and fluoroscopy. The total dose of lidocaine was kept below the recommended dosage limits, and the patients received midazolam and fentanyl to raise seizure threshold and decrease anxiety, which may contribute to the hypertension seen in the previous study.

\section{Comparison of lidocaine to RFA}

Gabrhelík et al in a pilot study compared the efficacy of pulsed RFA of the greater occipital nerve versus GONB with a mixture of local anesthetic and steroid in the management of refractory cervicogenic headache. ${ }^{12}$ They reported that pain remained reduced even after 9 months. Navani et al described a case of pulsed RFA of the GON obtaining 4 months' pain relief. ${ }^{13}$ Hamer and Purath performed continuous RFA of the
C2 dorsal root ganglion with or without third occipital nerve in an observational study of 40 patients with cervicogenic headache and occipital neuralgia. ${ }^{16}$ They reported a mean duration of pain relief at 22.35 weeks; however, $12.5 \%$ of the study patients reported hyperesthesia along the GON and lesser occipital nerve on the side treated. This lasted between 1 and 6 months at the time of follow-up. The use of cooled RFA was limited to a single case report and only the acute response was measured. ${ }^{15}$ The duration of GONB with $10 \%$ lidocaine at 148 days appeared to be at least comparable in duration to pulsed RFA and continuous RFA without the side effects. No dysesthesia was reported by any of the $10 \%$ lidocaine GONB patients.

\section{Conclusion}

In this case series, $10 \%$ lidocaine does appear to prolong the relief of headache and may have neurolytic action without side effects. The study was limited by its retrospective nature, small number of patients, and nonstandardized time for follow-up requiring self-report by patients. Given that, further investigation with a randomized controlled trial is warranted to confirm results. Also, further studies are needed to see if $10 \%$ lidocaine is a viable alternative to RFA of the occipital nerve in the treatment of headache.

\section{Disclosure}

The authors report no conflicts of interest in this work.

\section{References}

1. Biondi D, Bajwa Z. Cervicogenic headaches; 2007. Available from: UpToDate.com. Wolters Kluwer Health.

2. Olesen J, Steiner TJ. The international classification of headache disorders, 2nd ed. (ICDH-II). J Neurol Neurosurg Psychiatry. 2004;75(6):808-811.

3. Blumenfeld A, Ashkenazi A, Grosberg B, et al. Patterns of use of peripheral nerve blocks and trigger point injections among headache practitioners in the USA: results of the American headache society interventional procedure survey (AHS-IPS). Headache. 2010;50(6): 937-942.

4. Dilli E, Halker R, Vargas B, Hentz J, Radam T, Rogers R, Dodick D. Occipital nerve block for the short-term preventative treatment of migraine: a randomized, double-blinded placebo-controlled study. Cephalalgia. 2015;35(110):959-968.

5. Ashkenazi A, Young WB. The effects of greater occipital nerve block and trigger point injection on brush allodynia and pain in migraine. Headache. 2005;45(4):350-354.

6. Lambru G, Abu Bakr N, Stahlhut L, McCulloch S, Miller S, Shanahan P, Matharu MS. Greater occipital nerve blocks in chronic cluster headache: a prospective open label study. Eur J Neurol. 2014;21(2):338-343.

7. Naja ZM, El-Rajab M, Al-Tannir MA, Ziade FM, Tawfik OM. Repetitive occipital blockade for cervicogenic headache . Pain Pract. 2006;6(40):278-284.

8. Piovesan EJ, Kowacs PA, Oshinsky ML. Convergence of cervical and trigeminal sensory afferents. Curr Pain and Headache Rep. 2003;7(5): $377-383$. 
9. Busch V, Jakob W, Juergens T, Schulte-Mattler W, Kaube H, May A. Functional connectivity between trigeminal and occipital nerves revealed by occipital nerve blockade and nociceptive blink reflexes. Cephalalgia. 2006; 26(1):50-55.

10. Siddiqui F, Caplinger A. Efficacy of greater occipital nerve block with or without bupivacaine in chronic migraineurs. Neurology. 2013; 80(7):80-81.

11. Afridi SK, Shields KG, Bhola R, Goadsby PJ. Greater occipital nerve injection in primary headache syndromes - prolonged effects from a single injection. Pain. 2006;122(1-2):126-129.

12. Gabrhelík T, Michalek P, Adamus M. Pulsed radiofrequency therapy versus greater occipital nerve block in the management of refractory cervicogenic headache-a pilot study. Prague Med Rep. 2011;112(4) 279-287.

13. Navani A, Mahajan G, Kreis P, Fishman SM. A case of pulsed radiofrequency lesioning for occipital neuralgia. Pain Med. 2006;7(5):453-456.

14. Gazelka HM, Knievel S, Mauck WD, Moeschler SM, Pingree MJ, Rho RH, Lamer TJ. Incidence of neuropathic pain after radiofrequency denervation of the third occipital nerve. J Pain Res. 2014;7 195-198.

15. Vu T, Chhatre A. Cooled radiofrequency ablation for bilateral greater occipital neuralgia. Case Rep Neurol Med. 2014;2014:257373.

16. Hamer JF, Purath TA. Response of cervicogenic headaches and occipital neuralgia to radiofrequency ablation of the $\mathrm{C} 2$ dorsal root ganglion and/ or occipital nerve. Headache. 2014;54(3):500-510.

17. Wood KM. The use of phenol as a neurolytic agent: a review. Pain. 1978;5(3):205-229.

18. Swerlow M. Complications of neurolytic neural blockade. In: Cousins MJ, Bridenbaugh PHO, Editors. Neural Blockade and Clinical Management of Pain. Philadelphia: JB Lippincott; 1988:719-735.

19. Reid W, Kennedy W, Gray T. Phenol injection of the sympathetic chain. Br J Surg. 1970;57(1):45-50.

20. Kapur E, Vuckovic I, Dilberovic F, et al. Neurologic and histologic outcome after intraneural injections of lidocaine in canine sciatic nerves. Acta Anaesthesiol Scand. 2007;51(1):101-107.

21. Hashimoto K, Sakura S, Bollen AW, Ciriales R, Drasner K. Comparative toxicity of glucose and lidocaine administered intrathecally in the rat. Reg Anesth Pain Med. 1998;23(5):444-450.

22. Kalichman MW, Moorhouse DF, Powell HC, Myers RR. Relative neural toxicity of local anesthetics. J Neuropath Exp Neur. 1993;54(3): 234-240.

23. Kanai Y, Katsuki H, Takasaki M. Graded, irreversible changes in crayfish giant axon as manifestations of lidocaine neurotoxicity. Anesth Analg 1998;86(3):569-573.

24. Ready LB, Plumer MH, Haschke RH, Austin E, Sumi SM. Neurotoxicity of intrathecal local anesthetics in Rabbits. Anesthesiology. 1985;63(4):364-370.
25. Lambert LA, Lambert DH, Strichartz GR. Irreversible conduction block in isolated nerve by high concentrations of local anesthetics . Anesthesiology. 1994;80(5):1082-1093.

26. Bainton CR, Strichartz GR. Concentration dependence of lidocaine induced irreversible conduction loss in frog nerve. Anesthesiology. 1994;81(3):657-667.

27. Lirk P, Flatz M, Haller I, et al. In Zuker diabetic fatty rats, subclinical diabetic neuropathy increases in vivo lidocaine. Reg Anesth Pain Med. 2012;37(6):601-606.

28. Farber SJ, Saheb-Al-Zamani M, Zieske L et al. Peripheral nerve injury after local anesthetic injection. Anesth Analg. 2013;117(3):731-739.

29. Yang S, Abrahams MS, Hurn PD, Grafe MR, Kirsch J. Local anesthetic Schwann cell toxicity is time and concentration dependent. Reg Anesth Pain Med. 2011;36(5):444-451.

30. Perez-Castro R, Patel S, Garavito-Aguilar ZV, et al. Cytotoxicity of local anesthetics in human neuronal cells. Anesth Analg. 2009 108(3):997-1007.

31. Myers RR, Heckman HM. Effects of local anesthetics on nerve blood flow: studies using lidocaine with and without epinephrine. Anesthesiology. 1989;71(5):757-762.

32. Johnson ME, Uhl CB. Toxic elevation of cytoplasmic calcium by high lidocaine in a neuronal cell line. Reg Anesth 1997;22:A68.

33. Johnson ME, Uhl CB. Saenz JA, Dasilva AD. Lidocaine is more neurotoxic than bupivacaine, with a different mechanism of cytoplasmic calcium elevation. Reg Anesth. 1998;23:A30.

34. Schneider M, Ettlin T, Kaufman M, Schumacher P, Urwyler A, Hampl K, von Hochstetter A. Transient neurologic toxicity after hyperbaric subarachnoid anesthesia with 5\% lidocaine. Anesth Analg. 1993;76(5): 1154-1157.

35. Choi YK, Liu J. The use of 5\% lidocaine for prolonged analgesia in chronic pain patients: a new technique. RegAnesth Pain Med. 1998;23(1) 96-100.

36. Hempl KF, Schneider, Thorin D, Ummenhofer W, Drewe J. Hyperosmolarity does not contribute to transient radicular irritation after spinal anesthesia with hyperbaric 5\% lidocaine. Reg Anesth. 1995;20(5):363-366.

37. Kim DD, Asif A, Kataria S. Presentation of neurolytic effect of $10 \%$ lidocaine after perineural ultrasound guided injection of a canine sciatic nerve: a pilot study. Korean J Pain. 2016;29(3):158-163.

38. Keld DB, Hein L, Dalgaard M, Krogh L, Rodt SA. The incidence of transient neurologic symptoms (TNS) after spinal anaesthesia in patients undergoing surgery in the supine position. Hyperbaric lidocaine $5 \%$ versus hyperbaric bupivacaine 0.5\%. Acta Anaesthesiol Scand. 2000;44(3):285-90.

39. Sahai-Srivastava S, Subhani D. Adverse effect profile of lidocaine injections for occipital nerve block in occipital neuralgia. $J$ Headache Pain. 2010;11(6):519-523.

\section{Journal of Pain Research}

\section{Publish your work in this journal}

The Journal of Pain Research is an international, peer reviewed, open access, online journal that welcomes laboratory and clinical findings in the fields of pain research and the prevention and management of pain. Original research, reviews, symposium reports, hypothesis formation and commentaries are all considered for publication.

\section{Dovepress}

The manuscript management system is completely online and includes a very quick and fair peer-review system, which is all easy to use. Visit http://www.dovepress.com/testimonials.php to read real quotes from published authors. 